NBER WORKING PAPER SERIES

\title{
RISK PERCEPTION THROUGH THE LENS OF POLITICS IN THE TIME OF THE COVID-19 PANDEMIC
}

\author{
John M. Barrios \\ Yael Hochberg \\ Working Paper 27008 \\ http://www.nber.org/papers/w27008 \\ NATIONAL BUREAU OF ECONOMIC RESEARCH \\ 1050 Massachusetts Avenue \\ Cambridge, MA 02138 \\ April 2020
}

We thank Lauren Cohen, Francesco D'Acunto, Jonathan Dingel, Ray Fisman, Tarek Hassan, Seema Jayachandran, Elisabeth Kempf, Christian Leuz, Charlie McLure, Paola Sapienza, Andrei Shleifer, Kelly Shue, Margarita Tsoutsoura, Michael Weber, Constantine Yannelis, Luigi Zingales for helpful conversations, comments and suggestions. Jin Deng provided excellent research assistance. All errors are our own. We gratefully acknowledge the support of the Stigler Center and the Becker Friedman Center at the University of Chicago Booth School of Business. The views expressed herein are those of the authors and do not necessarily reflect the views of the National Bureau of Economic Research.

NBER working papers are circulated for discussion and comment purposes. They have not been peer-reviewed or been subject to the review by the NBER Board of Directors that accompanies official NBER publications.

(C) 2020 by John M. Barrios and Yael Hochberg. All rights reserved. Short sections of text, not to exceed two paragraphs, may be quoted without explicit permission provided that full credit, including $(\odot$ notice, is given to the source. 
Risk Perception Through the Lens of Politics in the Time of the COVID-19 Pandemic

John M. Barrios and Yael Hochberg

NBER Working Paper No. 27008

April 2020

JEL No. D8,I1,L82,P16

\begin{abstract}
$\underline{\text { ABSTRACT }}$
Even when, objectively speaking, death is on the line, partisan bias still colors beliefs about facts. We show that a higher share of Trump voters in a county is associated with lower perceptions of risk during the COVID-19 pandemic. As Trump voter share rises, individuals search less for information on the virus, and engage in less social distancing behavior, as measured by smartphone location patterns. These patterns persist in the face of state-level mandates to close schools and businesses or to "stay home," and reverse only when conservative politicians are exposed and the White House releases federal social distancing guidelines.
\end{abstract}

John M. Barrios

The University of Chicago

Booth School of Business

5807 S Woodlawn Ave

Chicago, IL 60637

john.barrios@chicagobooth.edu

Yael Hochberg

Jones Graduate School of Business

Rice University

6100 Main Street, MS-531

McNair Hall Room 331

Houston, TX 77005

and Massachusetts Institute of Technology

and also NBER

hochberg@rice.edu 


\section{INTRODUCTION}

Even when—objectively speaking — death is on the line, partisan bias still colors beliefs about facts. In this paper, we show that political beliefs have implications for risk perceptions and health-related decisions-such as social distancing behavior-in the COVID-19 pandemic. Because an individual's own risk of infection in a pandemic is determined by both their behavior and the externalities imposed on them by others with which they may have no choice but to interact, understanding how risk perceptions may vary across the population is critical to public health outcomes. If some populations infer lower risk from the same set of objective data (e.g., case counts and deaths), they may impose negative externalities on others in their community that may thwart policymaker attempts to flatten the curve. The increasing political divide in the U.S., and its reflection in where and how individuals consume news and, correspondingly, interpret facts, is thus of particular interest, as different news sources may present different interpretations of factual data, instilling different perceptions of risk in their viewers - who may in turn respond differently to information provision or suggested social distancing choices.

Risk perceptions are a key component of theories of behavioral change. Understanding how individuals form and update their expectations, and thus their behavior choices-particularly economic behavior-has been of critical interest to policymakers and academics alike. ${ }^{1}$ An emerging paradigm in this literature suggests that individuals exhibit considerable heterogeneity in expectations (e.g., D’Acunto et al., 2018; D’ Acunto et al. 2019a; D’Acunto et al. 2019b; Gennaioli et al., 2016; Coibion et al., 2019). Importantly, the notion that political beliefs affect individuals' perception of economic conditions is longstanding, dating back to Campbell et al. (1960). A large literature in political science (e.g., Iyengar et al., 2012; Mason, 2013; Lott and Hassett, 2014; Mason, 2015; Gentzkow, 2016; Boxell et al. 2017) documents an increase in political polarization over time, with political parties becoming increasingly homogeneous in the ideology of their members, and exhibiting increasing hostility toward members of the opposite political party. This body of literature demonstrates that individuals have an increased tendency to view the world through a "partisan perceptual screen," whereby their assessment of economic conditions and policies depend on whether their party of preference is currently in power (e.g., Bartels, 2002; Gaines et al., 2007; Gerber and Huber (2009); Curtin, 2006; Mian et al., 2018; Kempf and Tsoutsoura, 2019). ${ }^{2}$

Unlike prior settings in the literature where risk perceptions or expectations are confined to the economic realm, here, the setting affects health-related behavior, which could be viewed as non-partisan. Ultimately, a virus is agnostic to political party affiliation, in a health crisis, we might assume that everyone would seek at the best and more objective, accurate data. Yet because individuals' perception of the virus' threat may be influenced by where they source news or whether information comes from someone with similar or different political leanings than themselves, even a similar case or death count may be interpreted differently. Consider a setting in which

\footnotetext{
${ }^{1}$ Much of the work in this area has focused on inflation expectations, and relates cognitive ability to individuals' inflation forecasts.

${ }^{2}$ Evidence on how these partisan perceptions translate into differences in actual behavior and choices of economic agents, however, is mixed (see e.g., McGrath, 2017; Meeuwis, 2018; Mian et al, 2018; Makridis, 2019; Kempf and Tsoutsoura, 2019).
} 
individuals tend to consume information from news sources and authority figures that match their political beliefs, either because they have a preference for such news because of their political dispositions (Mullainathan and Shleifer, 2005) or because they believe the sources of such news are more credible (Gentzkow and Shapiro, 2006). At the outset of a potential crisis, while the same objective data is available to all, the individual observes a particular interpretation of that data-an interpretation whose message is shaped by political coloring associated with the media streams he consumes from. As different populations with different political preferences observe the same underlying data through different political lens (e.g. Gentzkow et al, 2018), they concentrate their forecasts accordingly, and ultimately, have different perceptions of the risk implied by an event-thus affecting their decisions and behavior.

More specifically, consider an individual who consumes news through media outlets that provide (pessimistic) projections regarding how a particular potential health crisis or pandemic might play out—potentially because such optimism (pessimism) serves other goals of the political group most closely associated with that news media outlet. Due to her choice of news outlet, the individual observes interpretations of data that downplay (exaggerate) the severity of the health threat, and as a result, views that new stream as being generated by a favorable (disfavorable) outcome scenario. The individual then places a higher probability weight on the favorable (disfavorable) scenario and neglects the risk of an alternative, worse (better) outcome. Even if the individual occasionally observes or hears of news stories that have a differing viewpoint or interpretation of the underlying data, these differing perspectives do not change his mind: he views the "bad news" stories as an aberration or misinterpretation of the data and continues to under-react-particularly so if those stories are associated with news outlets or authority figures that do not align with his political views, or are viewed as hostile to his views on other issues. Only when media outlets or authority figures associated with the individual's preferred political views begin to present different interpretations of the data, or when the disease hits close to home, does the individual adjust his perception of risk and change his behavior accordingly. ${ }^{3}$

Importantly, we are agnostic as to how particular political preferences arise - we simply take as given that some agents in the population hold different (here, conservative or liberal) political views. Moreover, we do not explicitly model why a certain political group may choose to prefer a particular interpretation of the data surrounding a health event, beyond the fact that political priors may affect which viewpoint is chosen. ${ }^{4}$ In particular, we take no stand on whether one political group is more correct than the other. We note that if one group misinterprets the underlying data and mistakenly underestimates the severity of the virus, it may have significant health outcome externalities; on the other hand, if a group overestimates the severity of the virus, it may least to extensive economic shutdown with large economic externalities.

\footnotetext{
${ }^{3}$ An alternative interpretation, which leads to similar conclusions, is that rather than perceiving objective data differently, individuals may not even attempt to gather objective data because their political leaders and the media they watch call it a hoax.

${ }^{4}$ For example, while it is possible that a party in power during a crisis will try to downplay the extent of the crisis for reelection purposes, it is also possible that the opposition party may exaggerate it to galvanize the population to seek change or to argue that the party in power mismanages crises.
} 
To explore the effects of political partisanship on risk perceptions in the pandemic context, we utilize a number of measures to capture risk perception and resulting behavior choices. The first set is based in Google Health Trends search data. Google search data have been employed in the economics literature in nowcasting exercises for retail sales (Choi and Varian, 2009a) and unemployment claims (Choi and Varian, 2009b), as well as for estimating levels of influenza activity (Ginsberg et al., 2009). Our first measure utilizes Google Health Trends data to measure search share for information regarding the virus (coronavirus, COVID-19, SARS-CoV2, Wuhan virus, Chinese virus, etc.). Our intuition for this measure is as follows: internet searches are a proxy for the demand for information which reflects an individual's level of concern about a topic. The higher the search share in a particular location and time period, the higher the perceived risk among that population. Our second measure in this set similarly uses Google Health trends to measure search share for unemployment-related terms (benefits, insurance, etc.), capturing individual's perceptions of the economic risk of the pandemic. We measure search share at the Nielsen Designated Market Areas (DMA) level at a daily frequency. Both measures of search follow expected patterns, rising sharply as the case load in the U.S. increases over time.

The second set of measures we employ reflects not only perception, but also resulting behavior choices, utilizing proprietary data obtained from Unacast, a large location data products company. Unacast collects and processes location data from a large sample of U.S. cellular phones to compute a variety of location-related measures at the county level. First, we use the change in average daily distance traveled from the pre-pandemic period. Specifically, for each day and for each county in the U.S., we obtain the percent change in the distance traveled in the county relative to the average for the same day of the week from the beginning of the year up to March 8th (the “pre-COVID period”). Second, for each day and for each county in the U.S., we obtain the percent change in visits to non-essential retail and services from the average for the same day of the week during the preCOVID-19 period. Essential locations include venues such as food stores, pet store and pharmacies. Non-essential retail and services include, but are not limited to, restaurants and bars, clothing stores, consumer electronics stores, cinemas and theaters, spas and hair salons, office supply store, gyms, car dealerships, hotels, hobby shops and so forth. Again, both measures follow expected patterns, decreasing sharply as the case load in the U.S. increases.

We begin by exploring the relationship between risk perceptions, as proxied by our search share measures, and political partisanship. Using specifications that control for various time-varying and invariant characteristics at the local level that could be related to fundamental risk as well as local economic activity, with our strictest specifications relying on within-DMA variation, we show that search share for both COVID-19 information and unemployment information decreases strongly in the share of voters in the county who voted from Donald J. Trump in the 2016 presidential election. ${ }^{5}$ Overall, search share for both types of terms is increasing in the number of confirmed cases announced, but this increase is muted in counties with higher Trump vote share (VS). To illustrate the magnitude of the effect, for every doubling of the number of confirmed COVID-19 cases, search

\footnotetext{
${ }^{5}$ For example, given that the spread of the COVID-19 is accelerated in highly dense locations, we control for population and population density. Our strictest specifications utilize Nielsen DMAs or county fixed effects.
} 
share for terms related to COVID-19 increases by $40 \%$, holding all else constant. For the same doubling of cases, a one standard deviation increase in the Trump VS (0.12) mutes this effect by $7.8 \%$.

We conduct two event studies around the first confirmed case and first confirmed death from COVID-19. Consistent with difference in risk perceptions, search share for COVID-19 terms increases sharply in low Trump VS counties surrounding the first case of COIV-19 in the county, relative to high Trump VS counties, and reverses pattern only surrounding the first confirmed death from COVID-19 in the county, with high Trump VS counties playing catch up once deaths are imminent.

While the search share results can be thought of as an attention measure that captures perceptions of risk, how this is reflected in behavior choices is unclear. We therefore next conduct similar analysis, replacing the search share outcomes with our social distancing measures. Consistent with our search share findings, we observe a negative overall relationship between the number of confirmed cases and the percent change in average daily distance traveled and in visits to non-essential businesses. Once again, this effect is muted in higher Trump VS counties. For every doubling of the number of confirmed COVID-19 cases in the county, the percent change in average daily change in distance traveled falls by 4.75 percentage points. For this same doubling in cases in the county, a one standard deviation increase in Trump VS in the 2016 election mutes this effect by 0.5 percentage points. Similar patterns are exhibited when we employ the change in daily visits to non-essential businesses as the outcome variable.

Over the course of the pandemic, state governments issued various directives regarding closure of nonessential businesses and schools and "stay home-work safe" (shelter-in-place). Furthermore, on March 16th, federal guidelines for social distancing for a 15-day period were announced. We use the variation within state across counties in Trump VS, and show that compliance with such directives varies substantially across high (Q4) and low (Q1) Trump VS counties. We show that in high Trump VS counties there is a significantly lower reduction in both average daily distance traveled and in visits to non-essential businesses, given the same directive in the same state, and holding county characteristics fixed.

Consistent with the hypothesis that political priors color interpretation of objective data, we show that these patterns shift considerably once Republican politicians begin to be affected by the pandemic. We exploit the emergence of COVID-19 infection in participants at the CPAC meetings that led to the announcement on March 9th that prominent Republicans including Senator Ted Cruz and the Chairman of CPAC were self-quarantined due to exposure to an individual with COVID-19. Following the March 9th announcement, high Trump VS counties shift their behavior, reducing daily distance traveled and visits to non-essential businesses more in response to confirmed cases. In essence, they begin to play catch-up: low Trump share counties, who already had reduced daily distance and non-essential visits considerably, continue to increase their level of social distancing as cases rise; high Trump VS counties do so at an even greater rate, roughly twice the magnitude of the continued reductions in low Trump VS counties. Moreover, when we map risk perceptions and responses before and after the CPAC announcement to the 2019 ratio of Google search share for Fox News to search share for MSNBC in the DMA, we observe that responses across the media ratio are much higher after the March 9th CPAC 
announcement. Particularly for the risk perception measures, the slope of the relationship between search share for COVID-19 terms and the FOX-to-MSNBC search ratio increases substantially post-CPAC (flips from downward sloping to upward sloping).

Our final set of analyses explore the relationship between our risk perception and social distancing measures and Trump VS for varying levels of high risk population (share of population over age 60) and ability to work from home. In both cases, we observe higher search share and greater social distancing where expected: when the share of the population over age 60 is higher, and in areas where the share of employment that can be done via telework (Dingel and Neiman, 2020) is higher. Even so, holding these elements constant, we continue to observe the divergence in response between high and low Trump VS counties, holding all else equal.

The implications of these differences in response could be quite significant. Pei and Shaman (2020), in their simulations of a transmission model for SARS-CoV2 with varying levels of reduction in contact rate between individuals, show that a $25 \%$ reduction in contact rate is enough to reduce the peak number of daily confirmed cases in the U.S. by 40\%, from 500,000 to 300,000. Pei and Shaman (2020) note that high reductions in both commuting and cross-county travel are needed to reduce the spread and rapid increase in infections.

Our findings make a number of distinct contributions to the existing literature. First, we contribute to the literature on expectations and risk perceptions. There has been a revived interest among economists over the last few years in understanding how households form and update their expectations, as well as the determinants of the cross-sectional variation in economic expectations across households (D’Acunto et al., 2019 and Gennaioli and Shleifer, 2018). While this literature focuses on household economic expectations, we contribute to the literature by showing another potential friction in the differential formation of individuals' expectations in the public health space. Specifically, we show that a similar expectation framework holds in what, at first, seems to be a less susceptible area for variation in risk perceptions: that of health risks during the height of a pandemic. Moreover, the fact that information on health risks passes through the lens of individuals' political priors, potentially determining variation in risk perceptions during the pandemic, provides insights into the development of policies to shape such risk perceptions in the general public. Finally, an open question remains of how the current pandemic will affect the expectation of households going forward in the post-pandemic period, and how that may then interact with individuals' political priors. ${ }^{6}$

Second, our work sheds light on the efficacy of certain types of policy interventions during a health pandemic. Our findings suggest that information treatments and requests for voluntary compliance with suggested behaviors may not be effective when different populations assess the riskiness of the situation differently due to their political leanings or the interpretations offered by political-leaning news organizations. This conclusion has a number of parallels to the large literature exploring the effects of risk perception on economic choice in the context of inflation expectations, which concludes that policies aimed to stimulate consumption expenditure may be less effective than theory implies given, for example, differing levels of cognitive ability among households

\footnotetext{
${ }^{6}$ Other large macro-economic shocks, such as the Great Depression and the Black Death, have been shown to have long-lasting effects on people’s attitudes towards risk (Malmendier and Nagel, 2009; D’Acunto et al. 2019).
} 
(D’Acunto et al., 2018; D’Acunto et al. 2019a; D’Acunto et al. 2019b). In this context, our work also related to new evidence that suggests that agents may form expectations differently based on some surprising heterogeneities, including traditional gender norms and the gender expectations gap (D’Acunto et al., 2020). The fact that information treatments and voluntary requests for social distancing may be viewed at differing levels of seriousness by groups of different political leanings suggests that such policies may lead to significant negative externalities for society as a whole. If a particular group chooses to ignore voluntary directives due to lower perceived risk, this affects more than just that group: an individual's actual risk in a pandemic is a function not only of that individual's own actions but also those of the individuals into which he comes in contact, willingly or unwillingly. While an individual whose perceptions of the risk of the pandemic are high may choose to be as precautious as possible, if her neighbors do not have the same perceptions of the risk, she may face a higher chance of being exposed to the disease.

Our third main contribution is to the literature on the effects of political polarization. Our findings demonstrate that polarization penetrates into our health-related choices and behavior, which have traditionally been viewed as nonpartisan. While the effects of political polarization on risk preferences have been documented in a variety of economic contexts, our paper is among the first to explore its effects on health-related behavior, and documents significant effects on choices and indicators of intended private consumption. While we know, for example, that individuals have a more optimistic view on future economic conditions when they are more closely affiliated with the party that controls the White House (e.g. Bartels, 2002), there is no clear evidence of these shifts in perceptions being reflected in actual household spending (Mian et al., 2018). In contrast, our findings demonstrate that the effects of political beliefs on risk perceptions in the COVID-19 pandemic led to a significant disparity in the reaction of households associated with different political party affiliation.

Finally, our paper speaks to the emerging literature on economic behavior and impacts in the COVID-19 pandemic. Eichenbaum et al. (2020), Barro et al. (2020) and Jones et al. (2020) present macroeconomic frameworks for studying epidemics. Gormsen and Koijen (2020) study the stock price and dividend future reactions to the epidemic, Baker et al. (2020) study household spending and debt responses to COVID-19, and Hassan et al. (2020) examine firm responses. Among this emerging literature, our paper is at the forefront of a new stream of timely research exploring the effects of political partisanship on pandemic responses from individuals and households. Other contemporaneous work in this area includes Alcott et al. (2020), who show differences in survey responses regarding perceived risk using a Facebook survey.

\section{COVID-19 PANDEMIC}

A pneumonia of unknown cause was first detected in the Wuhan province of China in early November 2019. The first cases were linked to a virus that was thought to be of animal origin. By December 2019, however, the spread of the infection was almost entirely driven by human-to-human transmission in the province. The virus, which was identified as a novel coronavirus, was labeled the Severe Acute Respiratory Syndrome Coronavirus 2 (SARS-CoV2), and the disease it inflicts in humans was labeled Novel Coronavirus Disease-2019 (COVID-19). 
The World Health Organization (WHO) declared the outbreak to be a Public Health Emergency of International Concern on January 30, 2020, and by March 11, upgraded the outbreak to a Pandemic status. As of the morning of April 6, 2020, over 1.3 million cases of COVID-19 have been reported worldwide, resulting in nearly 75,000 deaths (for real time case numbers, please see https:/www.worldometers.info/coronavirus/).

The first reported case in the U.S. was in Washington State on January 21, 2020, involving a male patient who had returned from Wuhan, China. Several other cases followed. The U.S. federal government established the White House Coronavirus Task Force on January 29. On February 26, the first case in the U.S. in a person with "no known exposure to the virus through travel or close contact with a known infected individual" was confirmed by the Centers for Disease Control and Prevention (CDC) in northern California, marking the beginning of community spread of the disease. In the days that followed, most major airlines suspended flights between the U.S. and China, and the Trump administration declared a public health emergency and announced restrictions on travelers arriving from China.

Because the major transmission vector for COVID-19 is through respiratory droplets and fomite (i.e., through close contact and by respiratory droplets produced when people cough or sneeze), efforts to prevent the virus primarily focus on preventing exposure. These include travel restrictions, quarantines, curfews, workplace hazard controls, event postponements and cancellations, facility closures, work-from-home, and voluntary or mandatory social distancing efforts.

\section{DATA SOURCES}

Our study uses a diverse set of novel datasets to explore the relation between risk perceptions and political polarization. We obtain the COVID-19 case counts and deaths from the Centers for Disease Control and Prevention (CDC), search trends data at the Nielsen DMA-level from Google Health Trends, and the measures of average change in daily travel distance and average change in visits to non-essential businesses and services for residents in a county by county-day from a large location data products company. We integrate political, social and demographics data from numerous other standard datasets. Detailed information about each dataset is provided in the online Appendix, with a summary of the variables used displayed in online Appendix Table 1. Below, we describe our key variables of interest.

\section{A. COVID-19 Cases and Deaths}

We compute both number of confirmed COVID-19 cases and deaths in a DMA (county) each day to capture the presence of the virus in U.S. We rely on an API from the COVID Tracking Project to obtain this data. ${ }^{7}$ The Project obtains data on cases and deaths from COVID-19 from state/district/territory public health authorities (or, occasionally, from trusted news reporting, official press conferences, and social media updates from state public health authorities or governors). The data includes the location and date of each case and death, allowing us to geo-assign them to a county-day.

\footnotetext{
${ }^{7}$ https://coronavirus.1point3acres.com/en.
} 


\section{B. Google Health Trends Search Share}

We utilize the Google Health Trends interface to extract data on two types of searches which inform our knowledge of risk perceptions during the pandemic: searches for COVID-19 related terms (COVID-19, SARSCoV2, coronavirus, Wuhan virus, Wuhan pneumonia, Chinese virus) and searches for unemployment-related terms (using the corresponding Google freebase identifier). The standard Google Trends index, which scales results from 0 to 100 based on the most popular term entered, does not easily allow comparisons across geographic areas and time periods. Instead, we use data from the Google Health Trends API, which describes how often a specific search term is entered relative to the total search volume on Google's search engine within a geographic region and time range, and returns the probability of a search session that includes the corresponding term for that region and time period. This makes comparisons across locations and time feasible. ${ }^{8}$ We track trends for searches for these terms using the Google Health Trends API for all Nielsen DMAs at daily frequency beginning in November 2019 to March 31st.

\section{Social Distancing Measures}

We obtain two measures that capture social distancing behavior (SDB) from Unacast, a large location data products company. The company combines granular location data from tens of millions of anonymous mobile phones and their interactions with each other each day and then extrapolates the results to the population level. The data spans the period of February $24^{\text {th }}$ to March $31^{\text {st }}, 2020$. The data provided to us includes the change of average daily distance traveled from baseline (avg. distance traveled for same day of week during pre-COVID19 time period for a specific county) and the change in visits to non-essential retail and services from baseline (avg. visits for same day of week during non-COVID-19 time period for a specific county), with the pre-COVID period defined as January 1, 2020 to March $8^{\text {th }}$, 2020. The company uses the guidelines issued by various state governments and policymakers to categorize venues into essential vs. non-essential, with essential locations including venues such as food stores, pet stores, and pharmacies. They then calculate the average visitation for each day of the week prior to the COVID-19 outbreak (defined as March 8th and earlier) as a baseline, and compare those baselines to visits on the corresponding days of the week post-outbreak (March 9th to the present). By always comparing Saturdays to Saturdays, Tuesdays to Tuesdays, and so forth, social distancing in these measures is captured in the context of the normal visitation rhythm of the 7-day week.

\section{Partisanship Measure}

\footnotetext{
${ }^{8}$ These probabilities are calculated on a uniformly distributed random sample of $10 \%-15 \%$ of Google web searches. Mathematically, the numbers returned from the Google Trend API can be officially written as:

Value $_{[\text {time,term restriction }]}=P($ term - restriction $\mid$ time and geo - restriction $) * 10 \mathrm{M}$

This probability is multiplied by 10 million in order to be readable.
} 
To proxy for political partisanship at the DMA or county level, we utilize data from the U.S. Presidential Election of 2016, obtained from the MIT Election Data Science and Lab (MEDSL). ${ }^{9}$ For each county, we calculate the share of voters that voted for Donald J. Trump in the 2016 election. ${ }^{10}$

\section{FINDINGS}

We begin our analysis in Exhibit 1 by examining the relationship between our risk perception and social distancing measures and the increasing spread of the Covid-19 pandemic in the U.S. Panel A of Exhibit 1 plots the average search shares for COVID-19 (left panel) and unemployment terms (right panel) by calendar time against the cumulative share of confirmed COVID-19 cases in the U.S. Panel B plots the percentage change versus baseline in average daily distance traveled and visits to non-essential businesses. Consistent with search shares reflecting perceptions of risk, we see a drastic increase in search for COVID-19 as initial cases appear in the U.S. This search behavior levels off towards the end of March, when much of the population has already educated themselves about the virus. Search for unemployment terms rises sharply beginning mid-March, as cases begin to increase rapidly and state-level closures of non-essential businesses begin to come under consideration, and continue to grow with the increasing economic uncertainty of the pandemic spread in the U.S. consistent with these proxies for increased perception of risk associated with the virus, both daily distance traveled and visits to non-essential businesses fall sharply as search shares for the virus rise. ${ }^{11}$

\section{A. Political Partisanship and Risk Perceptions (Online Search)}

Our first formal analysis explores the relationship between online search activity and Trump VS. Panel A of Exhibit 2 presents bin-scatters relating search shares for COVID-19 (left panel) and Unemployment Benefits (right panel) to the Trump VSs in U.S. DMAs. Each of the plots controls for the log number of confirmed cases, population density, income per capita, population, the day of the week, and the number of days since the first case in the DMA. Increases in Trump VS are associated with decreases in both search share measures. This negative association provides preliminary evidence on the variation of risk perceptions across political leanings.

We formally investigate this relationship in the following multivariable regression, estimated at the DMA level. We include the six days before and the six days after the first case appears in a county. We estimate the model:

$$
\begin{aligned}
& \log \left(\text { Search Share }_{d, t}+1\right)
\end{aligned}
$$

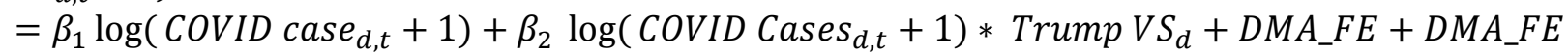

$$
\begin{aligned}
& * d a y+\varepsilon_{d, t}
\end{aligned}
$$

The dependent variable is the log of one plus the search share, with COVID-19 in the first set of specification and unemployment terms in the second set. We regress our search share measures on the log number of confirmed

\footnotetext{
${ }^{9}$ The data is available at https://dataverse.harvard.edu/dataset.xhtml?persistentId=doi:10.7910/DVN/LYWX3D.

10 Appendix Figure 1 Panel A plots the Trump VS by county in the 2016.

${ }^{11}$ Appendix Figure 1 Panel C plots when areas researched their peak search level for COVID-19. In Panel D we plot when the percentage change in our two measures of county social distancing first fell by 30\% in each county. Data is through March $28,2020$.
} 
COVID cases and include DMA fixed effects to capture various time invariant risk factors in the areas as well as allow for a DMA-specific linear trend. ${ }^{12}$ To examine differential response, we interact the log number of cases with the DMA Trump VS. In some specifications we replace Trump VS with an indicator variable for the DMA is in the highest quartile of DMAs with respect to Trump VS (High Trump). Standard errors are clustered at the DMA level.

Panel B of Exhibit 3 displays the results of our estimation. Columns (1) and (4) include the confirmed case count and the DMA FE; columns (2) and (5) add an interaction with Trump VS and the DMA specific linear trends; columns (3) and (6) replace the vote share with the indicator for High Trump DMA. In all specifications, we observe a positive relationship between the case count and the search shares. Importantly, however, the interaction models indicate that this positive relationship is muted in areas with higher Trump VS. Consider column (3). A 10\% increase in the number of confirmed cases increases search share by 7\%. For the High Trump DMAs, however, this is essentially canceled out by the interaction term. We observe similar patterns of coefficient signs for search for unemployment in columns (3)-(5). ${ }^{13}$

Panel C of Exhibit 2 presents an event study for changes in search shares surrounding two inflection points: the first confirmed case in a DMA and the first confirmed death. Low Trump VS DMAs search almost 40\% more than high Trump VS DMAs surrounding the first reported case in the DMA. High Trump VS DMAs appear to play catch up when the first death occurs.

\section{B. Social Distancing Behavior and Political Partisanship}

Having established systematic differences in the perception of risks around COVID-19 cases for high and low Trump VS areas, we next move to examine how these different perceptions manifest in individuals’ SDB. In Exhibit 3, Panel A we present bin scatter plots relating percentage changes in daily travel distance (left panel) and percentage changes in the number of visits to non-essential businesses (right panel) to Trump VS in the counties, once again controlling for observables related to the risk of COVID-19, as in Exhibit 2(A). The plots show that increased Trump VS is negatively (positively) associated with decreases (increases) in daily distances and nonessential trips.

We formalize this analysis in Panel B with a regression analysis similar to that conducted for the search share measures above, replacing the dependent variable with the two SDB measures. We estimate the regression at the county level, with county fixed effects and county-specific linear trends, and cluster standard errors at the county level. The estimates suggest that SDB increases in confirmed cases (as cases go up, the change in distance goes down, becoming more negative), and this effect is again muted in high Trump VS areas. Consider columns (3) and (6). In (3), the coefficient on log cases is -0.04 , and the coefficient on the interaction of log cases with the

\footnotetext{
${ }^{12}$ We also run the models without DMA fixed effects to examine the relation of various observable risk factors with search volume (unreported). Results remain unchanged.

${ }^{13}$ We show robustness to our estimates in Appendix Figure 2 Panel A. The figure plots the estimate of the coefficient on the interaction between log number of cases and Trump VS for several alternative specifications (controls for national cases, Day and DMA FE). We do this for both search share outcomes. Our inferences remain unchanged.
} 
High Trump VS indicator is 0.02; in other words, the effect of an increase in confirmed cases is muted by $50 \%$. In (6), the respective coefficients are -0.05 and 0.02 , a muting of $40 \%{ }^{14,15}$

\section{IV.B.1. $\quad$ Social Distancing Compliance around State Mandates}

Of course, some SDB may be driven by state-level orders to close school and businesses or "stay home work safe."16 Our next analysis examines the potential differential response for High Trump VS areas to these different state-level declarations. In Panel C of Exhibit 3, we estimate the following regression:

$$
\begin{aligned}
& \text { Social Distancing Behavior }{ }_{d . t} \\
& \qquad \beta_{1} \text { Post Fed } 15 \text { Days to Slow }+\beta_{2} \text { Post State Mandating Stay Home } \\
& +\beta_{3} \text { Post State Mandating Bus\&School Close }+\beta_{4} \text { Post Fed } 15 \text { Days to Slow } \\
& + \text { High Trump Vote Share }+\beta_{5} \text { Post State Mandating Stay Home } * \text { High Trump VS } \\
& +\beta_{6} \text { Post State Mandating Bus\&School Close } * \text { High Trump VS }+ \text { County_FE }+\varepsilon_{d, t}
\end{aligned}
$$

As can be seen from the table and figure, even in the presence of stay-at-home mandates, within a state, and holding all else constant, High Trump VS counties exhibit less SDB, reducing distance traveled less. We observe similar patterns for changes in non-essential business visits. Only when the Federal order to "slow the spread” arrived from the White House do High Trump counties begin to catch up. To put this in perspective, consider the estimates presented in the Figure: when state mandate the closure of non-essential businesses and schools, Low Trump VS areas reduce average daily travel distance by 9.3\%, whereas High Trump VS areas reduce by only $6.7 \% .{ }^{17}$ The difference in behavior for stay-at-home mandates is even larger.

\section{IV.B.2. $\quad$ COVID-19 at the CPAC meeting and Self-Quarantine of Republican Politicians}

In the introduction, we hypothesized that the difference in behavior for different politically-leaning groups may be driven by media streams from which they consume news and the authority figures conveying interpretation of that news. Exhibit 4 examines SDB surrounding the March $9^{\text {th }}$ announcement that Republican politicians and conservative activists were exposed to COVID-19 at the annual CPAC meetings the previous week, and that some had entered self-quarantine. Importantly, the announcement was a change in information only, not a change in fundamental risk for the counties. Nevertheless, we observe that High Trump VS areas change their behavior significantly following the announcement, reducing daily distance traveled by a factor of almost 2 relative to low

\footnotetext{
${ }^{14}$ Appendix Figure 2 Panel B reports the estimates of the difference in SDB graphically for high vs. low Trump VS counties. Here, we regress our SDB measures on the interaction of High Trump and day indicators. We report three specifications for each outcome. One includes county and day FE, one further adds state-day FE and the last adds controls for cases and death counts. The figures show a clear difference between high Trump VS areas as March began. This difference is still present even after controlling for state-day fixed effects as well as controlling for COVID-19's presence in the counties.

${ }^{15}$ Appendix Figure 2 Panel C examines the sensitivity of our estimates to sample composition by plotting the coefficient of the interaction between Log Number of Cases and Trump VS from Exhibit 3 Panel B (specifically the specifications in columns 2 and 5) after removing one state from the estimation at a time and re-estimating the specification.

${ }^{16}$ In Appendix Figure 1 Panel B we provide a map of the U.S. which depicts the states adopting mandatory stay at home orders.

${ }^{17}$ Consistent with this, in contemporaneous analysis using household data, Baker et al. (2020) show that Republicans spend more going out after these mandates than Democrats.
} 
Trump VS areas - essentially, catching up now that the risk is made salient by the fact that political figures on "their side" have been affected. Because this is a difference-in-difference framework, the coefficient is a differential between the high Trump VS and low Trump VS counties.

The media source hypothesis is further supported when we examine risk perception in the form of search shares for COVID-19 pre- and post-CPAC as a function of the average ratio of Fox News searches to MSNBC News searches on google in the DMAs during 2019. Each of the plots control for the log number of confirmed cases, population density, income per capita, population, the day of the week, the number of days since the first case in the DMA. In the pre-CPAC period, the relationship between the Fox News to MSNBC search share ratio and searches for COVID-19 is negative; this reverse and becomes a positive relationship post-CPAC, consistent with Fox News viewers playing catchup once their “own” are affected.

\section{IV.B.3. Partisanship and Risk Perception Heterogeneity: Old Age and Telework}

Our final set of analyses explore the relationship between our risk perception and social distancing measures and Trump VS for varying levels of high risk population (share of population over age 60) and ability to work from home. Exhibit 5 Panel A examines the relationship between the share of the population over 60 and search share (top row) and changes in the daily distance traveled (bottom row). For each measure, we examine both the fundamental relationship (left column) and the differential effect based on high Trump VS (right column). Each of the plots control for the log number of confirmed cases, population density, income per capita, population, the day of the week, and the number of days since the first case in the DMA or county. As expected, search for COVID-19 is higher when a higher percentage of the population is at high risk (older than 60). Consistent with the previous findings, this effect is muted in High Trump VS areas.

Panel B conducts similar analysis examining the relationship between SDB and the share of the workforce that can easily conduct work from home (Telework). The Telework measure is obtained from Dingel and Neiman (2020). ${ }^{18}$ In the left column we examine the fundamental relation while in the right column we examine the differential effect based on high Trump VS counties. In areas where the share of employment that can be done via telework is higher, SDB is greater (distance traveled is lower). Even so, we continue to observe the divergence in response between high and low Trump VS counties, holding all else equal.

\section{CONCLUSION}

The contention that partisanship is an active force, resulting in meaningful differences in beliefs and expectations, is a striking claim made in a nascent literature in economics. In this paper we provide an indication of the broad scope of such partisan influence by examining politically-driven variation in risk perceptions during the current COVID-19 pandemic. Using novel data on individuals' search behavior on Google and geospatial mapping data capturing changes in individuals’ daily travel distance and trips to non-essential businesses and

\footnotetext{
${ }^{18}$ Dingel and Neiman (2020) classify the feasibility of working at home for all occupations, and merge this classification with occupational employment counts for the United States.
} 
service locations, we document a significant divergence in the reactions of areas to COVID-19 cases with high and low Trump VS areas in the 2016 election. We document a muted response to preliminary cases in high Trump VS areas - even as state governments imposed a variety of school and business closures and stay-at-home recommendations - with a catch-up in attention only after prominent Republican figures were quarantined following the announcement of COVID-19 exposure at the annual CPAC meeting.

As countries across the world struggle to flatten the curve of the pandemic and lessen the possibility of significant deaths and prolonged economic contraction, understanding how individuals and households react to information treatments and voluntary compliance measures becomes of ever more importance to the ultimate resolution of the current crisis. Our findings suggest that risk perceptions and-consequently—behavioral choices, may be shaped through the lens of politics, rendering certain types of interventions that rely on uniform interpretation of the risk associated with the outbreak less effective. While many questions remain for future research, the findings provide initial insights that may guide the path of future theoretical and empirical work. 


\section{REFERENCES}

Baker, S., Farrokhnia, R.A., and Meyer, S., and Pagel, M., and C. Yannelis. How does household spending respond to an epidemic? Consumption during the 2020 COVID-19 pandemic (March 31, 2020).

Barro, R. J., Ursúa, J. F., \& Weng, J. (2020). The coronavirus and the great influenza pandemic: Lessons from the "spanish flu” for the coronavirus's potential effects on mortality and economic activity (No. w26866). National Bureau of Economic Research.

Bartels, L. M. (2002). Beyond the running tally: Partisan bias in political perceptions. Political behavior, 24(2), 117-150.

Boxell, L., M. Gentzkow, and J. M. Shapiro (2017). Greater internet use is not associated with faster growth in political polarization among us demographic groups. Proceedings of the National Academy of Sciences 114 (40), 10612-10617.

Campbell, Angus, P., W. Miller, and D. Stokes (1960). The American Voter. New York: Wiley.

Choi, H., \& Varian, H. (2009). Predicting initial claims for unemployment benefits. Google Inc, 1-5.

Coibion, O., Y. Gorodnichenko, and M. Weber (2019). Monetary policy communications and their effects on household inflation expectations (No. 25482). NBER Working Paper.

D’Acunto, F., D. Hoang, M. Paloviita, and M. Weber (2019a). Cognitive abilities and inflation expectations. AEA Papers and Proceedings 109, 562-566.

D’Acunto, F., D. Hoang, M. Paloviita, and M. Weber (2019b). Human frictions in the transmission of economic policy. SSRN Electronic Journal.

D’Acunto, F., D. Hoang, M. Paloviita, and M. Weber (2019c). IQ, expectations, and choice (No. 25496). Working Paper, National Bureau of Economic Research.

Dingel, J. and B. Neiman (2020). How Many Jobs Can Be Done At Home? BFI White Paper, Becker Friedman Institute.

Eichenbaum, M. S., Rebelo, S., \& Trabandt, M. (2020). The macroeconomics of epidemics (No. w26882). National Bureau of Economic Research.

Gaines, B. J., Kuklinski, J. H., Quirk, P. J., Peyton, B., \& Verkuilen, J. (2007). Same facts, different interpretations: Partisan motivation and opinion on Iraq. The Journal of Politics, 69(4), 957-974.

Gennaioli, N. and A. Shleifer (2010). What comes to mind. The Quarterly Journal of Economics 125(4), 1399-1433.

Gennaioli, N., Ma, Y., \& Shleifer, A. (2016). Expectations and investment. NBER Macroeconomics Annual, 30(1), 379431.

Gennaioli, N., A. Shleifer, and R. Vishny (2012). Neglected risks, financial innovation, and financial fragility. Journal of Financial Economics 104 (3), 452-468.

Gennaioli, N., A. Shleifer, and R. Vishny (2015). Neglected risks: The psychology of financial crises. American Economic Review 105 (5), 310-14.

Gerber, A. S. and G. A. Huber (2009). Partisanship and economic behavior: Do partisan differences in economic forecasts predict real economic behavior? American Political Science Review 103(3), 407-426.

Gentzkow, M. (2016). Polarization in 2016. Toulouse Network for Information Technology Whitepaper, 1-23. 
Gentzkow, M., and Shapiro, J. M. (2006). Media bias and reputation. Journal of Political Economy, 114(2), 280-316.

Gentzkow, M., Wong, M. B., \& Zhang, A. T. (2018). Ideological bias and trust in information sources. Working Paper.

Gormsen, N. J., \& Koijen, R. S. (2020). Coronavirus: Impact on stock prices and growth expectations. University of Chicago, Becker Friedman Institute for Economics Working Paper, (2020-22).

Hassan, T. A., and Hollander, S., van Lent, L., and Tahoun, A., Firm-level Exposure to Epidemic Diseases: COVID-19, SARS, and H1N1 (April 2, 2020).

Iyengar, S., G. Sood, and Y. Lelkes (2012). Affect, not ideological social identity perspective on polarization. Public opinion quarterly 76(3), 405-431.

Kempf, E. and M. Tsoutsoura (2018). Partisan professionals: Evidence from credit rating analysts. Technical report, National Bureau of Economic Research.

Lott, J. R. and K. A. Hassett (2014). Is newspaper coverage of economic events politically biased? Public choice 160(1-2), 65-108.

Mian, A. R., A. Sufi, and N. Khoshkhou (2018). Partisan bias, economic expectations, and household spending. FamaMiller Working Paper.

Mason, L. H. (2013). The polarizing effects of partisan sorting. In APSA 2013 Annual Meeting Paper.

Mason, L. (2015). "I disrespectfully agree”: The differential effects of partisan sorting on social and issue polarization. American Journal of Political Science, 59(1), 128-145.

MIT Election Data and Science Lab (2018). U.S. President Precinct-Level Returns 2016. https://doi.org/10.7910/DVN/LYWX3D, Harvard Dataverse, V11.

Mullainathan, S. and A. Shleifer (2005). The Market for News. American Economic Review 95(4), 1031-1053.

Pei, S. and J. Shaman (2020). Initial simulation of SARS-CoV2 Spread and Intervention Effects in the Continental US. Preprint, medRXiv. https://doi.org/10.1101/2020.03.21.20040303.

Vosen, S. and T. Schmidt (2011). Forecasting private consumption: survey-based indicators vs. Google trends. Journal of forecasting 30(6), 565-578. 


\section{EXHIBIT 1}

Panel A: Trends in Search Shares and COVID-19 Cases

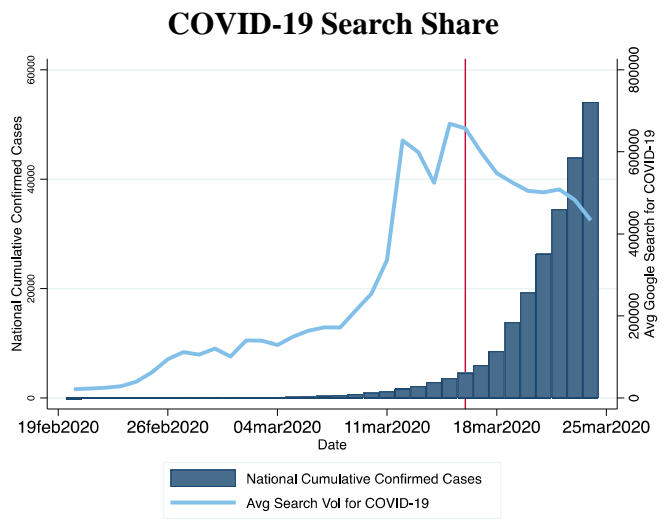

Unemployment Benefits Search Share

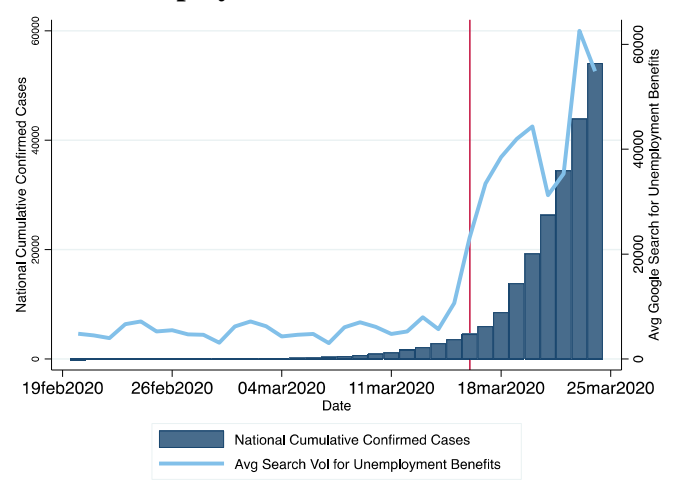

Panel B: Trends in Social Distancing Behaviors and COVID-19 Cases

Percentage Change In Avg. Distance Traveled

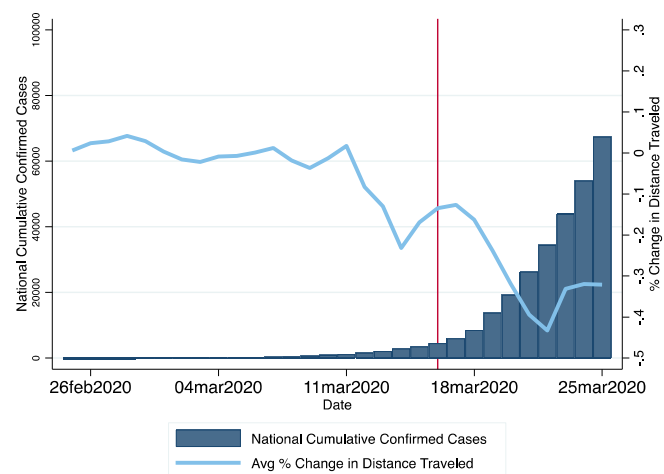

Percentage Change in Visits to Non-essential Business

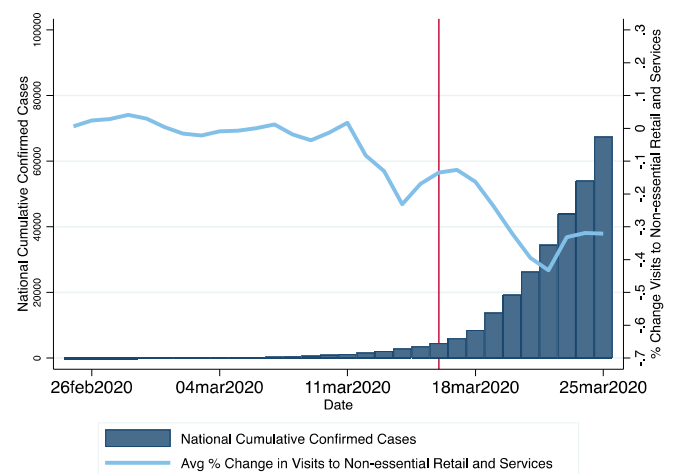

This exhibit plots the national average trends for each of our outcomes of interest over the first few months of 2020 against the cumulative number of confirmed COVID19 cases in the United States. In Panel A we plot the average search share for COVID-19 on google (left panel) as well as search share for unemployment benefits related terms (right panel). In Panel B we plot the average daily level of out two social distancing behavior. In the left panel we plot the daily average of the percentage change in distanced traveled in the county (relative to the pre-COVID period), while in the right panel we plot the daily average of the percentage change in visits to non-essential business in the county (relative to the pre-COVID-period). A red vertical line marks March 16 the day that the federal guidelines for social distancing where announced. 


\section{EXHIBIT 2}

Panel A: Search Share and Political Polarization - Trump Vote Share

COVID-19 Search Share

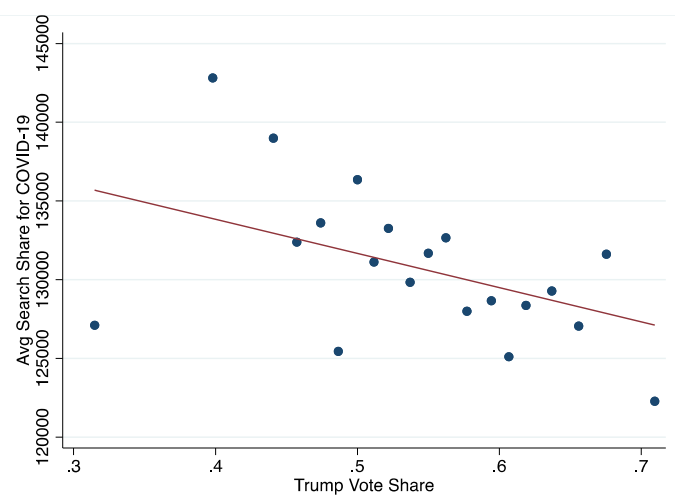

Unemployment Benefits Search Share

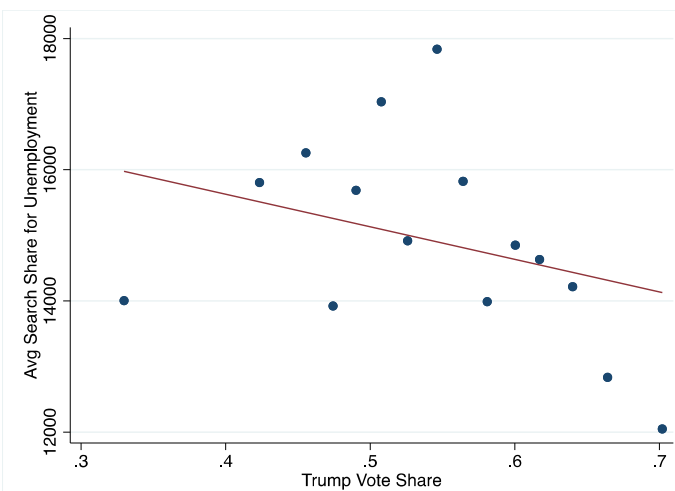

Panel A plots our two measures of search share on the Trump VS in the 2016 election in each of the Nielsen DMAs. The left panel uses COVID-19 search shares while on the right we use the search share for unemployment. Each of the plots control for the log number of confirmed cases, population density, income per capita, population, the day of the week, the number of days since the first case in the DMA.

Panel B: Changes in Search Shares around confirmed cases and political polarization

\begin{tabular}{|c|c|c|c|c|c|c|}
\hline \multirow[b]{2}{*}{ VARIABLES } & \multicolumn{3}{|c|}{ Log Search Vol COVID-19 } & \multicolumn{3}{|c|}{ Log Search Vol Unemployment } \\
\hline & (1) & (2) & (3) & (4) & (5) & (6) \\
\hline Log Num of Confirmed COVID Cases & $\begin{array}{c}0.29 * * \\
(0.02)\end{array}$ & $\begin{array}{c}0.41^{* *} \\
(0.14)\end{array}$ & $\begin{array}{l}0.07^{*} \\
(0.03)\end{array}$ & $\begin{array}{c}0.68^{* *} \\
(0.07)\end{array}$ & $\begin{array}{l}1.75^{*} \\
(0.67)\end{array}$ & $\begin{array}{l}0.18^{+} \\
(0.10)\end{array}$ \\
\hline Log Num COVID Cases X Trump Vote Share & & $\begin{array}{c}-0.65^{* *} \\
(0.24)\end{array}$ & & & $\begin{array}{c}-3.24^{* *} \\
(1.24)\end{array}$ & \\
\hline Log Num COVID Cases X High Trump Vote Share & & & $\begin{array}{c}-0.09+ \\
(0.05)\end{array}$ & & & $\begin{array}{c}-1.08^{* *} \\
(0.35)\end{array}$ \\
\hline Observations & 2,203 & 2,184 & 2,203 & 2,203 & 2,184 & 2,203 \\
\hline Adjusted R-squared & 0.685 & 0.849 & 0.848 & 0.303 & 0.389 & 0.382 \\
\hline Sample & DMA & DMA & DMA & DMA & DMA & DMA \\
\hline DMA FE & Yes & Yes & Yes & Yes & Yes & Yes \\
\hline DMA Linear Trend & No & Yes & Yes & No & Yes & Yes \\
\hline Mean Search Vol & 12.69 & 12.68 & 12.69 & 12.69 & 12.68 & 12.69 \\
\hline
\end{tabular}

Panel B provides a multivariate analysis on changes in search share with respect to COVID cases. The dependent variable is the log search share for COVID-19 (column 1-3) and Unemployment terms (column 4-6). In columns (1) and (4) we regress the search shares on the Log Number of confirmed COVID cases including DMA fixed effects. In columns (2) and (5) we interact the number of cases with the Trump Vote Share in each of the DMAs and include DMA specific linear trends. Finally, in columns (3) and (6) we replace the vote share with an indicator for High Trump Vote share DMAs (DMA is in the upper quartile of DMAs in trump vote share). Standard errors are clustered by DMA and are reported in parenthesis.

\section{Panel C: Event Studies: Changes in Search Shares around confirmed cases and deaths for high and low Trump vote share areas \\ First Confirmed COVID-19 Case \\ First COVID-19 Death}

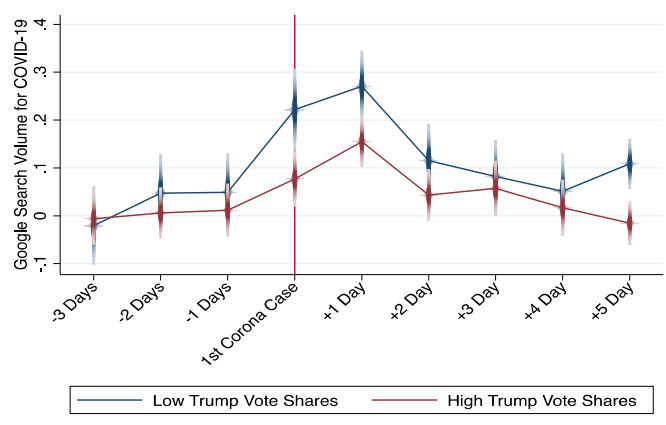

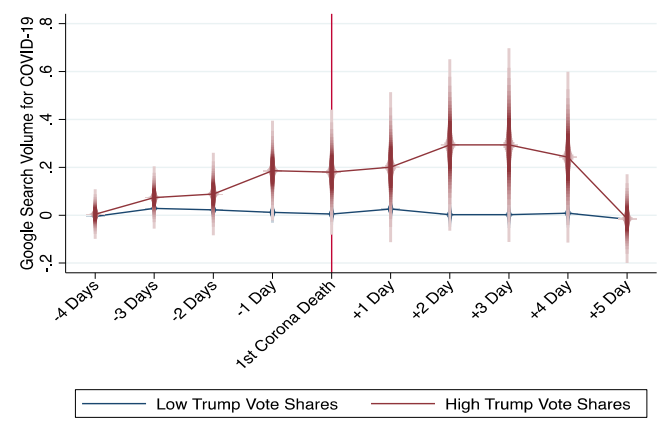

Panel C plots abnormal search share for COVID-19 relative to 5 days before the first confirmed case of COVID-19 in a DMA (left panel) and the first COVID-19 death (right panel). These estimates are done for high (red) and low (blue) Trump vote share DMAs. The estimates are obtained by estimating an OLS where the daily log search share is regressed on event time dummies. Each specification controls for DMA time invariant characteristics like population, per-capita income and density. We also control for calendar time trends via day fixed effects. Moreover, in the first death event study we also control for time since first confirmed case. 


\section{EXHIBIT 3}

Panel A: Social Distancing Behavior and Political Polarization - Trump Vote Share Percentage Change In Avg. Distance Traveled Percentage Change in Visits to Non-Essential Business
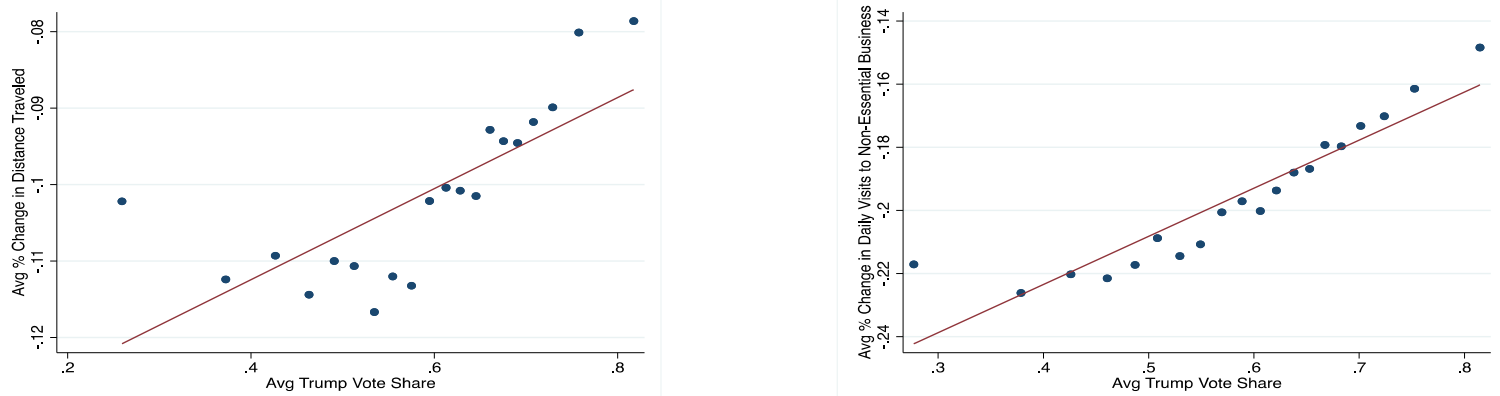

Panel A plots our two measures of county Social distancing on the Trump VS in the 2016 election in each of the counties. The left panel uses the percentage change in the average distance traveled in the county while on the right panel we examine the percentage change in visits to non-essential businesses in the county. Each of the plots control for the log number of confirmed cases, population density, income per capita, population the day of the week, and the number of days since the first case in the DMA.

Panel B: Changes in Social Distancing Behavior around confirmed cases and Political Polarization - Trump Vote Share

\begin{tabular}{|c|c|c|c|c|c|c|}
\hline \multirow[b]{2}{*}{ VARIABLES } & \multicolumn{3}{|c|}{ Perc Change in Distance Traveled } & \multicolumn{3}{|c|}{ Perc Change in Non-Essential Visits } \\
\hline & $(1)$ & $(2)$ & (3) & (4) & $(5)$ & (6) \\
\hline Log Num of Confirmed COVID Cases & $\begin{array}{c}-0.04^{* *} \\
(0.00)\end{array}$ & $\begin{array}{c}-0.05^{* *} \\
(0.00)\end{array}$ & $\begin{array}{c}-0.04^{* *} \\
(0.00)\end{array}$ & $\begin{array}{c}-0.04^{* *} \\
(0.00)\end{array}$ & $\begin{array}{c}-0.05^{* *} \\
(0.00)\end{array}$ & $\begin{array}{c}-0.05^{* *} \\
(0.00)\end{array}$ \\
\hline Log Num COVID Cases X Trump Vote Share & & $\begin{array}{c}0.04^{* *} \\
(0.01)\end{array}$ & & & $\begin{array}{c}0.03^{* *} \\
(0.01)\end{array}$ & \\
\hline
\end{tabular}

\begin{tabular}{lcccccc} 
Log Num COVID Cases X High Trump Vote Share & & & & & & $0.02^{* *}$ \\
& & & $0.02^{* *}$ & & & $(0.00)$ \\
\hline Observations & & & $(0.01)$ & & & 62,056 \\
Adjusted R-squared & 74,587 & 77,028 & 77,495 & 46,254 & 48,280 & 0.808 \\
Controls & 0.515 & 0.652 & 0.638 & 0.725 & 0.820 & Yes \\
Sample & Yes & Yes & Yes & Yes & Yes & County \\
Day FE & County & County & County & County & County & Yes \\
County FE & Yes & Yes & Yes & Yes & Yes & Yes \\
Mean of Dependent Variable & No & Yes & Yes & No & Yes & Yes \\
\hline
\end{tabular}

Panel B provides a multivariate analysis on changes in social distancing behavior with respect to COVID cases. The dependent variable is the percentage change in: distance traveled in the county (column 1-3) and non-essential visits (column 4-6). In columns (1) and (4) we regress the SD behavior on the Log Number of confirmed COVID cases including day fixed effects as well as controls for county population, density, per-capita income and time since first case. In columns (2) and (5) we interact the number of cases with the Trump Vote Share in each of the counties while in columns (3) and (6) we replace the vote share with an indicator for High Trump Vote share counties (counties is in the upper quartile of counties in trump vote share). Columns (2), (3), (5), and (6) include county fixed effects. Standard errors are clustered by county and are reported in parenthesis.

Panel C: Political Partisanship and Compliance with National and State Social Distancing Measures

\begin{tabular}{lcc} 
Differential Changes in SD Behavior Around & \multicolumn{3}{c}{ State } & Mandates \\
\hline & $\mathbf{( 1 )}$ & $\mathbf{( 2 )}$ \\
\hline VARIABLES & Per Chg Dist & Per Chg Visit \\
\hline & $-0.08^{* *}$ & $-0.18^{* *}$ \\
Post Fed 15 Days to Slow & $(0.00)$ & $(0.01)$ \\
& $-0.08^{* *}$ & $-0.07^{* *}$ \\
Post State Mandating Stay Home & $(0.00)$ & $(0.00)$ \\
& $-0.08^{* *}$ & $-0.15^{* *}$ \\
Post State Mandating Bus \& School Closure & $(0.00)$ & $(0.01)$ \\
& $-0.03^{* *}$ & -0.00 \\
High Trump Vote Share X Post Fed 15 Days to Slow & $(0.01)$ & $(0.01)$ \\
& 0.01 & 0.02 \\
High Trump Vote Share X Post State Mandating Bus \& School Closure & $(0.01)$ & $(0.01)$ \\
& $0.02^{* *}$ & $0.05^{* *}$ \\
High Trump Vote Share X Post State Mandating Stay Home & $(0.01)$ & $(0.01)$ \\
\hline Observations & 77,495 & 48,352 \\
Adjusted R-squared & 0.459 & 0.718 \\
Control for Number of Cases & Yes & Yes \\
Sample & County & County \\
County FE & Yes & Yes \\
Mean of Dependent Variable & -0.13 & -0.14 \\
\hline
\end{tabular}

Chg. Distance \& High/Low Trump Counties

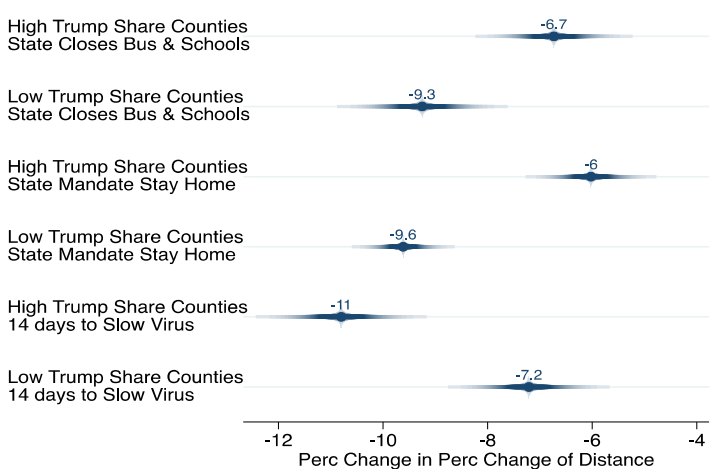

Panel C provides a multivariate analysis of changes in social distancing behavior around the adoption of various measures at the state and federal level to motivate the citizenry to engage in social distancing. Specifically, we focus on the federal regulations to slow the virus, state regulations that closed schools and businesses, and states adopting mandatory stay at home orders. On the right panel, we run a multi-variable regression where we regress our two measures of social distancing on various indicators for the federal and state orders. To examine the differential social distancing behavior by trump areas, we interact with the indicators an indicator for High Trump Vote share counties. Each specification includes controls for the log number of confirmed cases and county fixed effects. Standard errors are clustered by county. Finally, the right panel we plot the cumulative reaction concerning changes in distance traveled for high and low trump counties around each of the orders along with .95 confidence intervals. These are estimated from the specification in column 1 but using only the high and low trump counties. 


\section{EXHIBIT 4}

Panel A: COVID-19 Scare at CPAC and Changes in Social Distancing Behavior

CPAC and Changes in Distance Traveled

Post CPAC Anouncement
Low Trump Share Counties

(1)
CPAC and Changes in Non-Essential Visits

Post CPAC Anouncement Low T

Post CPAC Anouncement
High Trump Share Counties

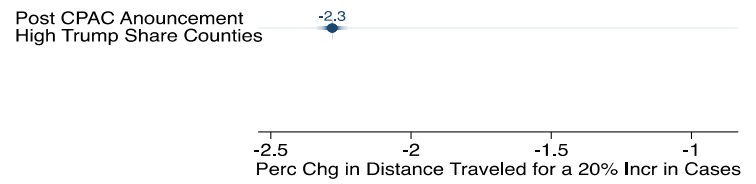

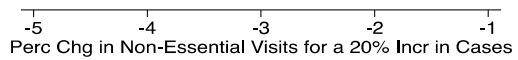

Panel B plots the cumulative change in the percentage change in distance traveled (left panel) and the percentage change in non-essential visits given an $20 \%$ increase in the number of confirmed after the CPAC announcement in high and low trump vote share counties. We obtain these estimates by estimating models like those in columns (1) and (2) in Panel C in Exhibit 3. Specifically, we augment the models by using a Post-CPAC indicator and interacting them with the base variables. Each plotted estimate include $95 \%$ confident intervals and standard errors are clustered at the county level.

\section{Panel B: COVID-19 Scare at CPAC and Risk Perceptions CPAC and Changes in Distance Traveled}

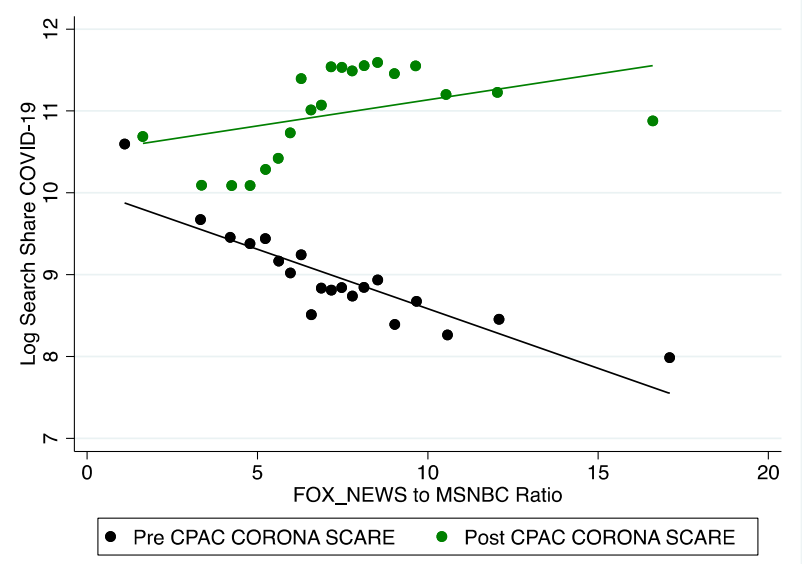

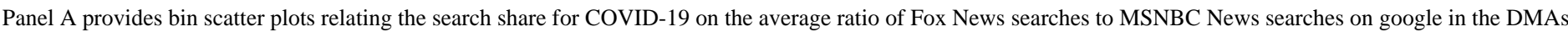

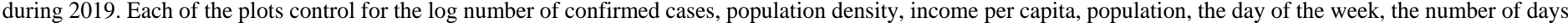

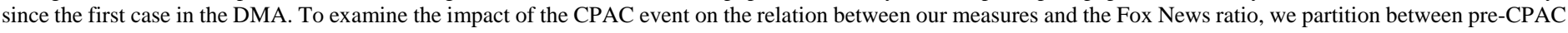
event searches and post-CPAC searches. 


\section{EXHIBIT 5}

Panel A: Risk Perceptions and Share of the Population Over 60

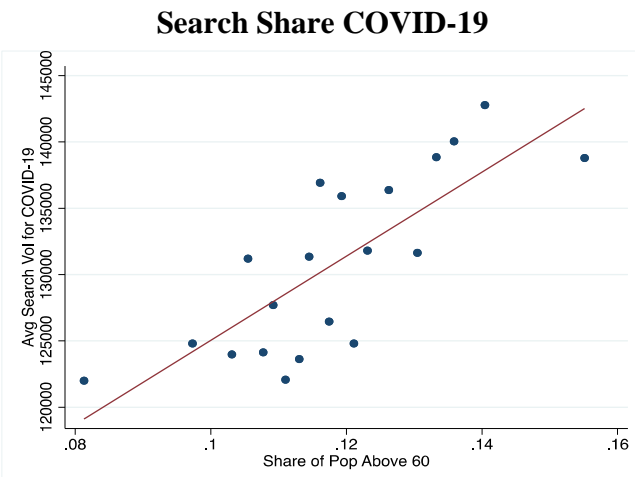

Percentage Change In Avg. Distance Traveled

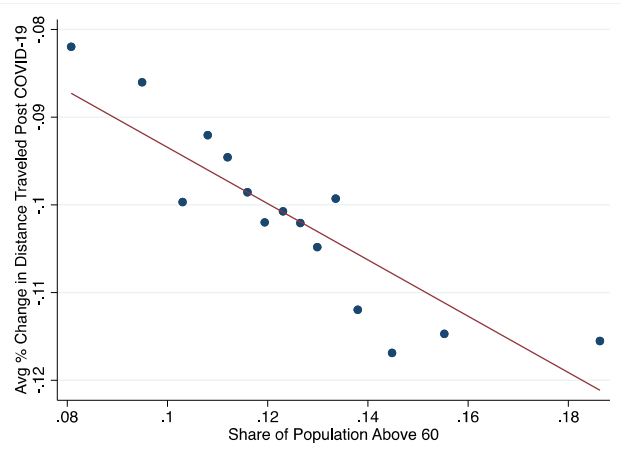

Political Polarization Interaction - Search Vol

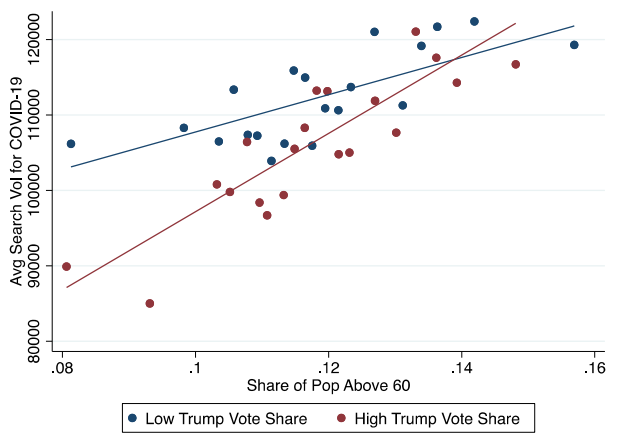

Political Polarization Interactions - Distance

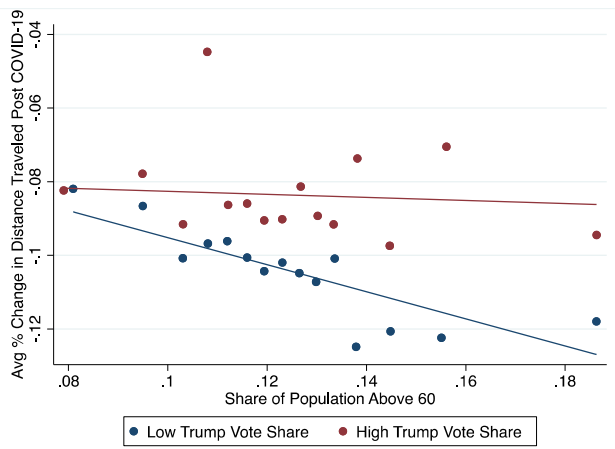

Panel A examines the relation between the share of the population over 60 and search share (top row) and changes in the daily distance traveled (bottom row). For each measure we examine both the fundamental relation (left column) and the differential effect based on high Trump VS. The search share panels are measured at the Nielsen DMA level while the daily travel distance change is measure at the county level. Each of the plots control for the log number of confirmed cases, population density, income per capita, population, the day of the week, and the number of days since the first case in the DMA or county.

Panel B: Social Distancing Behavior and Teleworking

\section{Percentage Change In Avg. Distance Traveled}

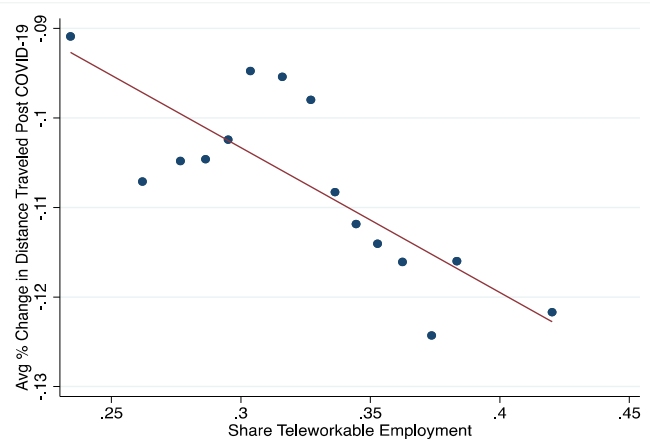

Political Polarization Interactions

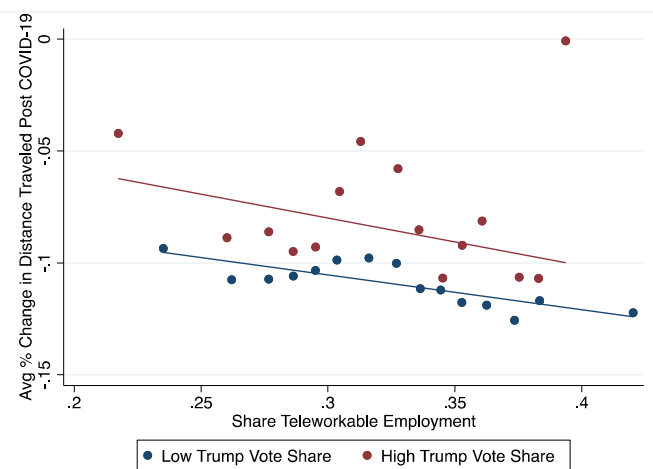

Panel B examines the relation between social distancing behavior and the share of the workforce that is easily done at home (Telework). The Telework measure is obtained from Dingel and Neiman (2020). They classify the feasibility of working at home for all occupations and merge this classification with occupational employment counts for the United States in the left column we examine the fundamental relation while in the right column we examine the differential effect based on high Trump VS counties. Each of the figures control for the log number of confirmed cases, population density, income per capita, population, the day of the week, and the number of days since the first case in the DMA or county. 


\section{APPENDIX}

\section{Appendix Table 1}

Panel A: Google Health Trends Search Share Data

\begin{tabular}{|c|c|c|c|c|c|c|c|c|c|c|c|c|}
\hline & \multicolumn{4}{|c|}{ (1) } & \multicolumn{4}{|c|}{ (2) } & \multicolumn{4}{|c|}{ (3) } \\
\hline & \multicolumn{4}{|c|}{ All } & \multicolumn{4}{|c|}{ Low Trump Vote Share DMA } & \multicolumn{4}{|c|}{ High Trump Vote Share DMA } \\
\hline & count & mean & $\mathrm{sd}$ & p50 & count & mean & sd & p50 & count & mean & $\mathrm{sd}$ & p50 \\
\hline Coronavirus related searches & 17556 & 131561.257 & 196053.503 & 40573.262 & 13272 & 133730.308 & 197344.597 & 41263.229 & 4284 & 124841.450 & 191865.625 & 38285.818 \\
\hline Employment related searches & 17556 & 9734.338 & 15473.465 & 5008.776 & 13272 & 9583.843 & 14961.284 & 4800.598 & 4284 & 10200.578 & 16955.725 & 6158.225 \\
\hline Number of Confirmed Cases & 17556 & 12.897 & 345.231 & 0.000 & 13272 & 16.869 & 396.977 & 0.000 & 4284 & 0.592 & 2.839 & 0.000 \\
\hline Number of New Confirmed Cases & 17347 & 3.118 & 84.183 & 0.000 & 13114 & 4.078 & 96.802 & 0.000 & 4233 & 0.146 & 0.786 & 0.000 \\
\hline Number of Death & 17556 & 0.191 & 3.511 & 0.000 & 13272 & 0.248 & 4.036 & 0.000 & 4284 & 0.015 & 0.132 & 0.000 \\
\hline Trump Vote Share & 17388 & 0.545 & 0.124 & 0.550 & 13104 & 0.495 & 0.099 & 0.512 & 4284 & 0.698 & 0.038 & 0.692 \\
\hline Population & 17052 & 1462530.256 & 2374613.111 & 735813.000 & 13020 & 1762752.871 & 2637978.371 & 910057.000 & 4032 & 493061.396 & 381135.800 & 362604.500 \\
\hline Income PerCap & 17556 & 42407.807 & 16373.080 & 40085.392 & 13272 & 43619.623 & 18383.766 & 41250.466 & 4284 & 38653.551 & 5740.302 & 38155.246 \\
\hline Pop Density & 17052 & 155.339 & 219.213 & 83.331 & 13020 & 182.528 & 243.084 & 98.895 & 4032 & 67.544 & 48.254 & 58.382 \\
\hline Percent of Pop Over 60 & 17556 & 0.118 & 0.018 & 0.116 & 13272 & 0.117 & 0.019 & 0.115 & 4284 & 0.121 & 0.014 & 0.120 \\
\hline Unique DMA & 209 & & & & 158 & & & & 51 & & & \\
\hline Observations & 17556 & & & & 13272 & & & & 4284 & & & \\
\hline
\end{tabular}

Panel A reports descriptive statistics on Google health trends search share data. The sample period is from Jan. 1, 2020 to Mar. $24,2020$. Column (1) provide descriptive statistics for the full sample. Column (2) and (3) shows statistics for the subsample of low trump vote share DMAs and high trump vote share DMAs.

\section{Panel B: Social Distancing Data}

\begin{tabular}{|c|c|c|c|c|c|c|c|c|c|c|c|c|}
\hline & \multirow{2}{*}{\multicolumn{4}{|c|}{$\begin{array}{l}\text { (1) } \\
\text { All }\end{array}$}} & \multicolumn{4}{|c|}{ (2) } & \multicolumn{4}{|c|}{ (3) } \\
\hline & & & & & & Low Trump & Vote Share Cou & & & High Trump V & /ote Share Cour & \\
\hline & count & mean & $s d$ & p50 & count & mean & $s d$ & p50 & count & mean & $s d$ & p50 \\
\hline $\begin{array}{l}\text { Per Change in Daily Driving Distanc } \\
\text { Per Change in Daily Visits to Non- }\end{array}$ & 103836 & -0.096 & 0.177 & -0.055 & 78710 & -0.101 & 0.178 & -0.057 & 25126 & -0.082 & 0.170 & -0.051 \\
\hline Essential Business & 70482 & -0.182 & 0.244 & -0.100 & 57902 & -0.193 & 0.250 & -0.105 & 12580 & -0.133 & 0.210 & -0.082 \\
\hline Number of Confirmed Cases & 288561 & 1.656 & 95.480 & 0.000 & 216853 & 2.185 & 110.135 & 0.000 & 71708 & 0.059 & 1.062 & 0.000 \\
\hline Number of New Confirmed Cases & 285390 & 0.000 & 56.846 & 0.000 & 214470 & 0.000 & 65.574 & 0.000 & 70920 & 0.000 & 0.609 & 0.000 \\
\hline Number of Death & 288561 & 0.024 & 1.446 & 0.000 & 216853 & 0.032 & 1.667 & 0.000 & 71708 & 0.001 & 0.044 & 0.000 \\
\hline Trump Vote Share & 287105 & 0.631 & 0.158 & 0.662 & 215397 & 0.573 & 0.140 & 0.606 & 71708 & 0.803 & 0.041 & 0.794 \\
\hline Population & 273546 & 99616.090 & 318962.946 & 25990.500 & 203112 & 127439.486 & 365849.554 & 35339.500 & 70434 & 19381.180 & 21811.014 & 12431.000 \\
\hline Income PerCap & 284921 & 5565245.018 & 20636094.709 & 1009854.000 & 213304 & 7174905.003 & 23625514.195 & 1435375.500 & 71617 & 771035.355 & 1028297.710 & 440974.000 \\
\hline Pop Density & 273546 & 230.043 & 1717.786 & 44.700 & 203112 & 297.230 & 1988.920 & 55.600 & 70434 & 36.295 & 45.472 & 22.100 \\
\hline Percent of Pop Over 60 & 284830 & 0.132 & 0.029 & 0.130 & 213213 & 0.129 & 0.029 & 0.127 & 71617 & 0.139 & 0.025 & 0.138 \\
\hline Unqiue County & 3171 & & & & 2383 & & & & 788 & & & \\
\hline Observations & 288561 & & & & 216853 & & & & 71708 & & & \\
\hline
\end{tabular}

Panel B reports descriptive statistics on social distancing data. The sample period is from Feb. 24, 2020 to Mar. 28, 2020. Column (1) provide descriptive statistics for the full sample. Column (2) and (3) shows statistics for the subsample of low trump vote share counties and high trump vote share counties. 


\section{Appendix Figure 1}

Panel A: Trump Vote Share by County

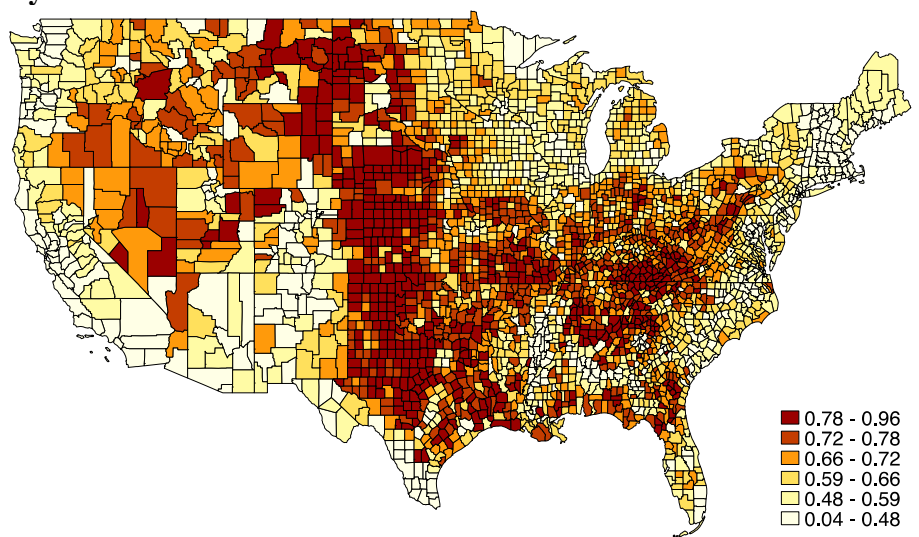

Panel A plots the Trump VS in the 2016 election in each of the counties. Data is obtained from the MIT Election Data Science and Lab (MEDSL).

Panel B: State Mandating Stay Home

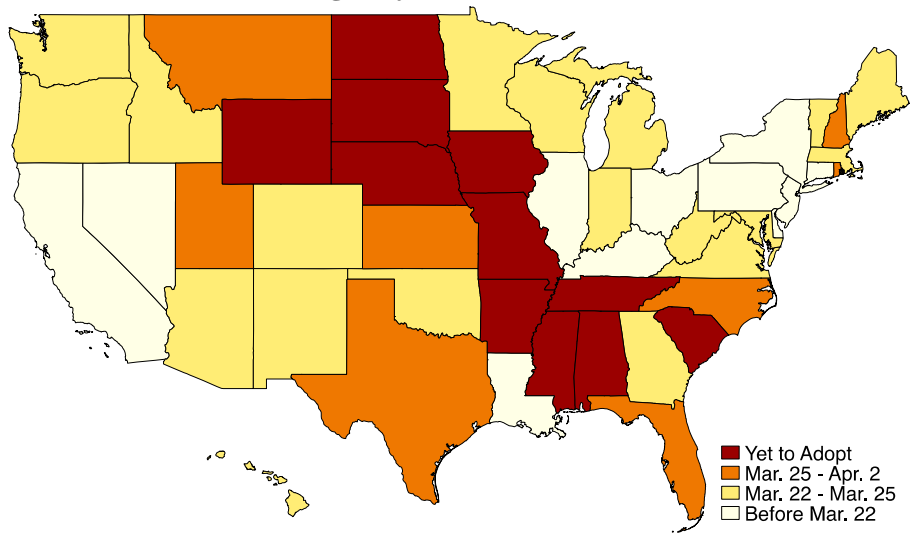

Panel C: Google Search Share - Day Peak Search Occured

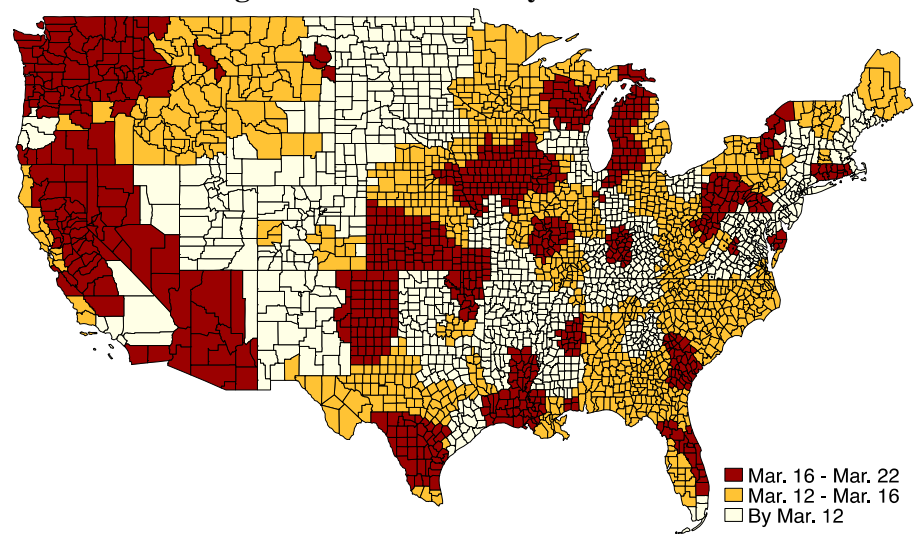

Panel B plots the date when each state government issued "Stay Home” (shelter-in-place) directive. Data is through April 2, 2020. Data is obtained from FINRA. ${ }^{19}$ Panel C plots the dates when the DMAs reached their peak search activity for COVID-19. Data is through March 31, 2020. The darker the shade the later the peak day in the county.

Panel D: Social Distancing Behavior

When Perc Change in Avg. Distance Traveled First Fell by 30\% When Perc. Change in Visits to Non-Essential Business First Fell by 30\%
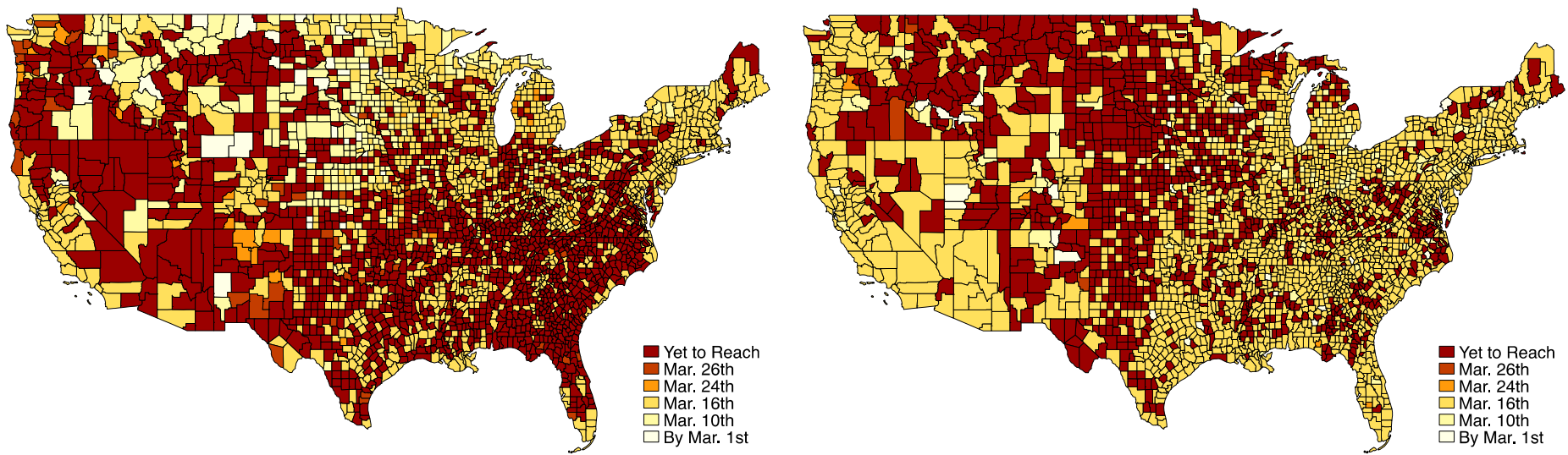

Panel D plots when percentage change in our two measures of county social distancing first fell by 30 in each of the counties. Data is through March 28,2020 . The left panel uses the percentage change in the average distance traveled in the county while on the right panel we use the percentage change in visits to non-essential businesses in the county.

${ }^{19}$ FINRA. https://www.finra.org/rules-guidance/key-topics/covid-19/shelter-in-place 


\section{Appendix Figure 2}

\section{Panel A: Trump Vote Share and Search Share - Robustness}

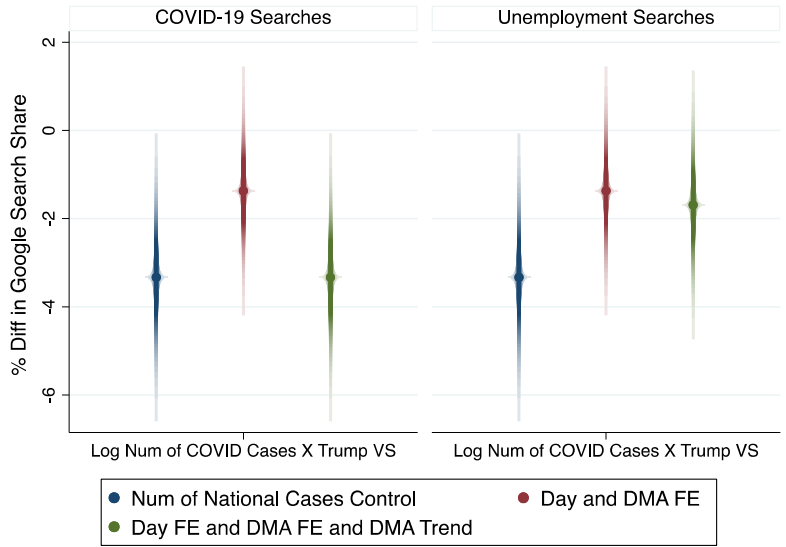

Panel A plots the interaction between the log number of local COVID-19 cases and trump VSs from Exhibit 2 Panel B under several alternative specifications for each of our search outcomes. Specifically, we add controls for the number of national COVID-19 cases in one, in a second specification we control for Day FE and DMA FE. Finally, we examine the estimates when, in addition to day and DMA fixed effects, we add DMA Linear trends. Each estimate includes a 95\% confidence interval obtained from standard errors clustered at the DMA.

\section{Panel B: Trump Vote Share and Social Distancing}

Percentage Change in Travel Distance.

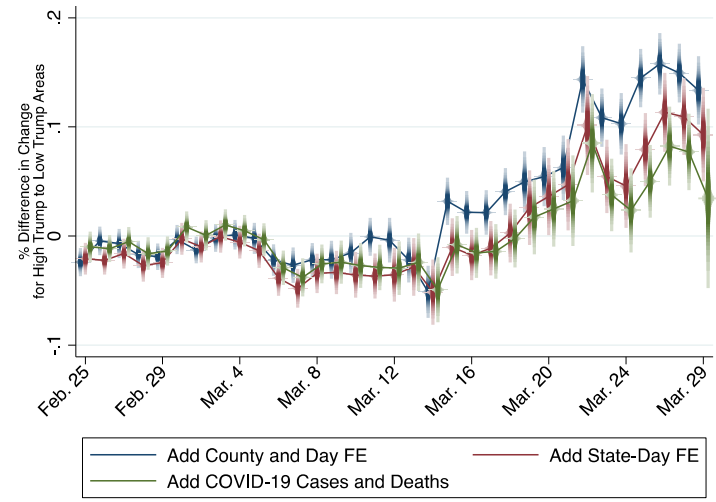

Percentage Change in Visits to Non-Essential Businesses

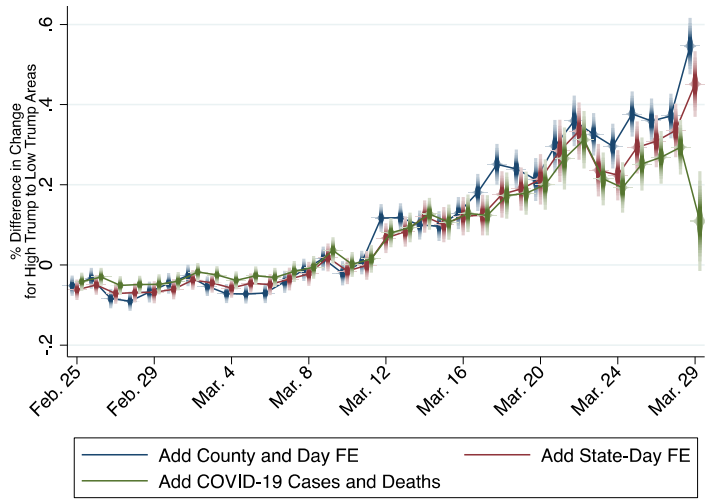

Panel A plots the differential changes in SDB (the percentage change in travel distancing (right panel) and visits to non-essential businesses) for High Trump VS counties to Low Trump by calendar time. The plotted estimates are obtained by regressing the SDB on the interaction between High Trump VS county and the day indicator. In each figure, we plot three specifications - including county and day fixed effects (blue), adding state by day fixed effects, and finally adding controls for COVID-19 cases and Deaths. The higher the coefficient, implies the lack of social distancing activities in high trump counties as compared to low trump share counties. Each of the estimates includes 95 percent confidence intervals. The standard errors to estimate these intervals are clustered at the county level.

\section{Panel C: Trump Vote Share and Social Distancing - Robustness to Sample Restrictions Outcome: \% Chg Distance Traveled}

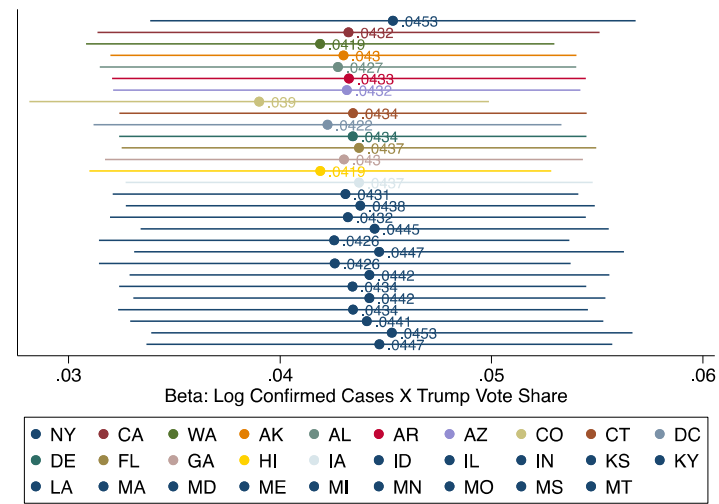

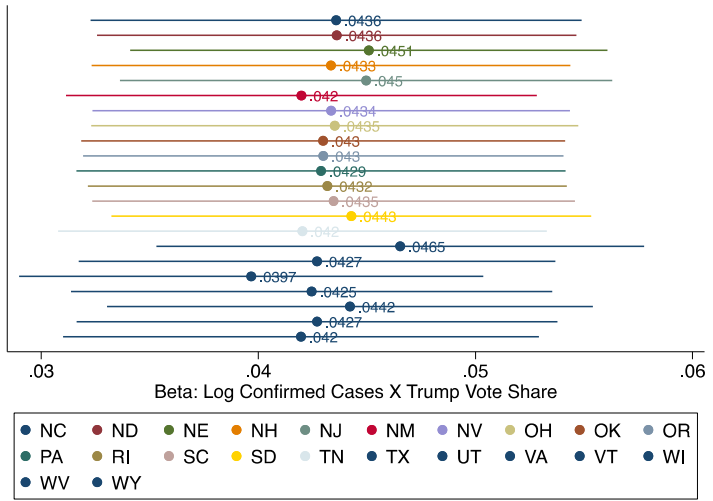




\section{Appendix Figure 2-Continued}

\section{Panel C: Trump Vote Share and Social Distancing - Robustness to Sample Restrictions}

Outcome: \% Chg Visits to Non-Essential Business
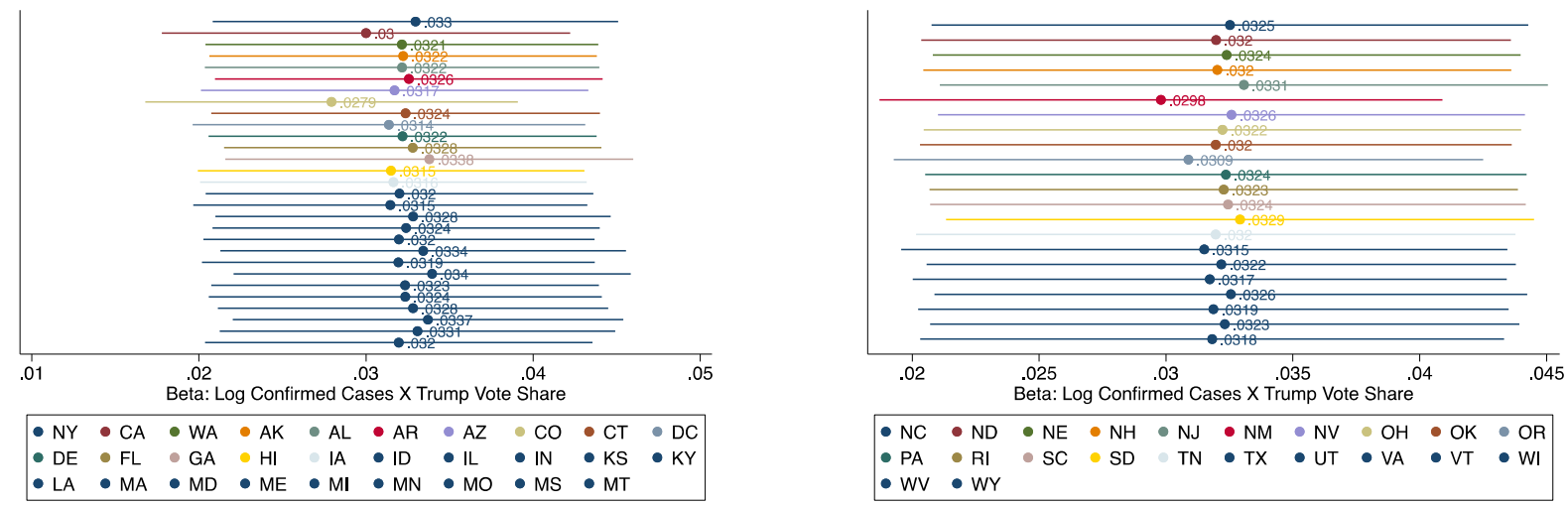

Panel C examines the sensitivity of our estimates for the SDB to sample composition by plotting the coefficient of the interaction between Log Num of Cases and Trump VS from Exhibit Three Panel B (specifically the specifications in columns 2 and 5) after removing one state from the estimation at a time and re-estimating the specification. The top subpanel displays the coefficient where percentage change in distance traveled is the outcome while the percentage change in visits to non-essential businesses is provided in the lower subpanel. 